\title{
Acquired Facial Nerve Palsy
}

National Cancer Institute

\section{Source}

National Cancer Institute. Acquired Facial Nerve Palsy. NCI Thesaurus. Code C116902.

A condition characterized by reduced or absent movement of the ipsilateral face as a

consequence of an injury to the seventh cranial nerve that has occurred after birth. 